\title{
Electromyographic activity during active prone hip extension did not discriminate individuals with and without low back pain
}

\author{
Atividade eletromiográfica durante o movimento de extensão do quadril em \\ prono não discrimina indivíduos com dor lombar
}

Cristiano Q. Guimarães, Ana C. L. Sakamoto, Glória E. C. Laurentino, Luci F. Teixeira-Salmela

\begin{abstract}
Background: Changes in activation of the trunk and hip extensor muscles can result in excessive stress on the lumbar spinal structures, predisposing them to lesions and pain. Objectives: To compare electromyographic activity of the gluteus maximus, semitendinosus and the erector spinae muscles between asymptomatic and individuals with low back pain during active prone hip extension exercises. Methods: Fifty individuals were recruited and divided into two groups: 30 asymptomatic ( $24.5 \pm 3.47$ years) and 20 with mechanical low back pain (28.75 \pm 5.52 years). They performed active prone hip extension exercises, while the activation parameters (latency, duration and quantity of activation) of the investigated muscles were recorded by electromyography. The beginnings of the movements were detected by a motion capture system. Differences between the groups were investigated employing Student $t$-tests or Mann-Whitney- $U$ tests, according to the data distribution. Results: No significant differences were found between the groups for any of the investigated muscles. Muscular activation patterns were similar for both groups, starting with the semitendinosus, followed by the erector spinae, and then, by the gluteus maximus. For both groups, significant delays in the onset of the gluteus maximus were observed. Conclusions: The assessment of the electromyographic activity was not capable of discriminating individuals with and without low back pain, suggesting an overlap in the studied populations.
\end{abstract}

Key Words: gluteus maximus; low back pain; activation patterns; electromyography, prone hip extension.

\section{Resumo}

Contextualização: Alterações no padrão de recrutamento dos extensores de tronco e quadril podem resultar em estresse excessivo sobre estruturas da coluna lombar, predispondo-a à lesão e dor. Objetivos: Comparar a atividade eletromiográfica dos músculos glúteo máximo, semitendíneo e eretores espinhais entre indivíduos assintomáticos e com dor lombar durante o exercício de extensão de quadril em prono. Métodos: Cinquenta indivíduos foram recrutados e divididos em dois grupos: 30 assintomáticos (24,5 $\pm 3,47$ anos) e $20 \mathrm{com}$ dor lombar (28,75 5,52 anos). Os parâmetros de ativação (latência, duração e quantidade de ativação) dos músculos investigados durante os exercícios de extensão de quadril foram registrados por meio da eletromiografia. O início e o término do movimento foram detectados por um sistema de análise de movimento. Diferenças entre os grupos foram investigadas utilizando-se teste $t$ de Student ou Mann-Whitney-U, dependendo da distribuição. Resultados: Não foram observadas diferenças significativas entre os grupos para nenhum dos músculos investigados. O padrão de recrutamento foi similar para os dois grupos, iniciando-se pelo semitendíneo, seguido pelos paravertebrais e finalizado pelo glúteo máximo. Nos dois grupos, observou-se um aumento significativo na latência do glúteo máximo comparado aos demais músculos. Conclusões: A avaliação do padrão de recrutamento não foi capaz de separar indivíduos com e sem dor lombar, sugerindo ocorrer uma sobreposição entre as populações estudadas.

Palavras-chave: glúteo máximo; dor lombar; padrão de ativação; eletromiografia; extensão do quadril.

Received: 04/05/2009 - Revised: 14/10/2009 - Accepted: 21/10/2009

Physical Therapy Department, Universidade Federal de Minas Gerais (UFMG), Belo Horizonte (MG), Brazil

Correspondence to: Luci Fuscaldi Teixeira-Salmela, Departamento de Fisioterapia, Universidade Federal de Minas Gerais, Avenida Antônio Carlos, 6627, Campus Pampulha,

CEP 31270-901, Belo Horizonte (MG), Brazil, e-mail: Ifts@ufmg.br 


\section{Introduction $\because \therefore$.}

Relationships between movement patterns and dysfunctions have been studied ${ }^{1,2}$ and movement is considered to be a system, which depends on the appropriate functional and interactions between several elements: basic systems (muscular and skeletal), modulator system (nervous), and the biomechanical and support systems ${ }^{2}$. Each element plays an important role in movement production and can be, in turn, be modified due to the adaptative physiological responses of the tissues ${ }^{3}$.

Sustained postures or incorrect movement habits may modify the demands made of the involved muscles, leading to changes in strength, flexibility, stiffness or activation patterns ${ }^{4,5}$. As a consequence, changes in movement patterns may emerge, thus spreading the physical stresses across various structures, which results in impairments of the muscular and skeletal systems ${ }^{1,2}$.

Adequate muscular activation patterns, when the synergic muscles are activated in an appropriate temporal order, are recognized to be important for the effective functioning of the lumbar spine ${ }^{5}$. Even if these muscles have adequate strength and, if the nervous system does not activate them at the right moment and with an adequate intensity, movement impairments can still result ${ }^{4}$, and contribute to low back pain (LBP).

Active prone hip extension exercises have been used to evaluate the activation patterns of the lumbar pelvic region. These movements involve the contraction of the gluteus maximus, hamstring, and erector spinae muscles. In asymptomatic individuals, it has been discussed whether there are characteristic activation patterns and, if so, what would they be. There is no consistency concerning ideal activation levels, which makes the identification of altered patterns difficult in the evaluation process $^{6-9}$.

Studies which evaluated the activation patterns during the active prone hip extension exercises in individuals with LBP were not found. It is possible that these individuals show lower variability, as suggested by Nygren Pierce and Lee ${ }^{7}$, a delayed activation of the gluteus maximus, compromizing the lumbar pelvic stabilization; or changes in other muscular parameters. The identification of differences between LBP and asymptomatic individuals may help in the understanding of the link between altered muscular activation and pain, besides enhancing the comprehension of the important outcome measures which should be assessed.

Therefore, the aims of this study were to compare the activation patterns between asymptomatic and LBP individuals and to investigate changes in the electromyographic activation parameters (latency, duration and amount of muscular activation) of the trunk and hip extensor muscles in individuals with LBP, during active prone hip extension exercises.

\section{Methods $\because \because$.}

\section{Subjects}

Fifty individuals of both genders were recruited from the community and divided into two groups. Thirty asymptomatic subjects, without complaints of pain, histories of trauma nor surgery in the lumbar spine or lower limb joints were selected. Twenty individuals with mechanical LBP, who had pain with a duration over at least six months, a history of at least one episode of LBP which had limited their functional activities in work or sports over the past 18 months, and had experienced episodes of LBP over the past six months were also selected.

Exclusion criteria included the presence of pain during the tests, shortening of the hip flexors, as determined by a positive Thomas test ${ }^{9}$, neurological disorders, pain in the thoracic spine and/or in the lower limbs, a history of fractures or surgery in the lumbar spine or hip joints, pregnancy in the two previous years, and the presence of tumors or infections. Those who were submitted to a physical therapy program, which involved strengthening of the extensors of the trunk or hip, and those taking analgesics were also excluded.

The groups were matched by age, gender, and physical activity levels. All participants signed a consent form to participate in the study, which was approved by the ethical review board of the Universidade Federal de Minas Gerais, Brazil (Parecer ETIC 422/06).

\section{Instrumentation}

The activation parameters (latency, duration and amount of activation) of the gluteus maximus, semitendinosus, and erector spinae muscles were assessed by electromyography (MP150WSW, Biopac Systems Inc. ${ }^{\oplus}$, Santa Barbara, CA). This device had two amplifiers connected to a microcomputer, which had an input impedance of $2 \mathrm{M} \Omega$ and a CMRR of 1,000 M $\Omega$ and allowed data acquisition at frequencies from 10 to 1,000 Hz. Data were collected at a frequency of 1,000 Hz. Active, bipolar surface electrodes (TSD 150), with diameters of $13.5 \mathrm{~mm}$ and an impedance of $100 \mathrm{M} \Omega$ were used for data collection.

The beginning of the movement was detected by a motion capture system ProReflex MCU Qualisys (QUALISYS MEDICAL AB, Gothenburg, SW), with an acquisition rate of $120 \mathrm{~Hz}$ and MCU 120 digital cameras equipped with a set of infra-red light emitters which were reflected by spherical passive markers of $12 \mathrm{~mm}$ in diameter and adhered to specific anatomic 
bony marks. Procedures of linearization and calibration were performed according to the instructions in the manufacturer's manual. Three cameras were employed to capture the images and were positioned in such a way that all markers were captured during the performance of the active prone hip extension.

\section{Procedures}

Demographic and anthropometric data were collected on all subjects, as well as other clinically relevant information. Thus, the subjects in both groups were asked to answer the short version of the International Physical Activity Questionnaire (IPAQ), to evaluate their physical activity levels ${ }^{10}$. The individuals with LBP were submitted to a physical examination to verify the inclusion criteria and characterize the direction of the spinal movement which triggered their pain (flexion and/or extension). They also replied to three questionnaires for characterization purposes: The Tampa Scale for KinesiophobiaBrazil, to assess their fear of movement/reinjury ${ }^{11}$; the Roland Morris-Brazil, to evaluate their functional limitation and disability levels ${ }^{12}$; and the Qualitative Pain Scale, which evaluated their pain on a six-point scale ${ }^{12}$.

To obtain the EMG data, surface electrodes $(\mathrm{Ag} / \mathrm{AgCl})$ were placed in pairs parallel to the muscular fibers ${ }^{8,13}$. For the gluteus maximus, the electrodes were placed at the midpoint of the line running from the last sacral vertebrae to the greater trochanter; for the semitendinosus, medially on the mid-distance point between the gluteal fold and the knee joint; and for the erector spinae muscles, at the L3 level, bilaterally two cm lateral from the spinal processes and parallel to the lumbar spine. The inter-electrode spacing was two $\mathrm{cm}$ from center to center. The reference electrode was placed over the lateral malleolus, and skin preparation included shaving, rubbing and cleansing with alcohol.

Passive markers were then placed over the iliac crest and the greater trochanter (forming one rigid segment) and the mid-point of the thigh and the lateral epicondyle of the femur (forming another segment) of the dominant lower limb. The subjects were instructed to perform active prone hip extension at their natural speed (Figure 1). Three trials were obtained during a two-minute rest period between each trial and the mean values of the three trials were used for analysis. The peak EMG values obtained during the movement were used as reference points for data normalization. The beginnings of the movements were determined by the changes in the angular displacements of the rigid segments, obtained from the motion capture system. A trigger mechanism was used to synchronize the EMG and the motion capture system data, after assuring EMG silence. The collected data were stored and exported to Matlab for processing and analysis.

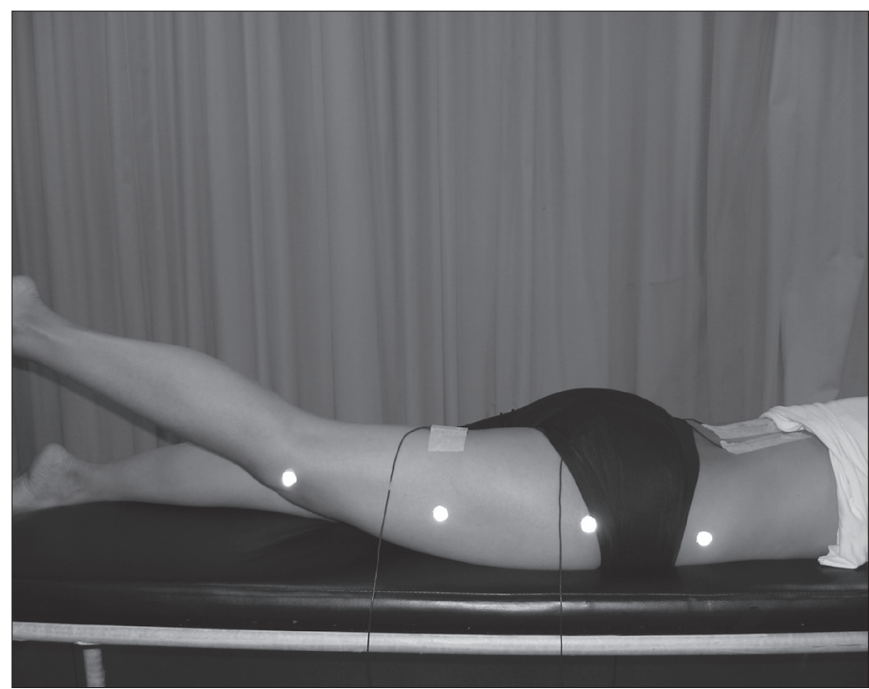

Figure 1. Participant performing the active prone hip extension movements.

\section{Data reduction}

EMG data processing was performed using the Acknowledge software. The EMG signals were full-wave rectified and low-pass and high-pass filtered with cut-off frequencies of 500 and $10 \mathrm{~Hz}$, respectively. The quantification of the EMG signals was based upon peak root mean square (RMS) values from the dynamic contractions during the active prone hip extension.

Muscular activation patterns were described after determining the EMG onset for each muscle. The onset and the end of the muscular activity were considered to occur when the values respectively exceeded and dropped below two standard deviations from the mean values observed at baseline for a $50 \mathrm{~ms}$ period $^{14}$. The onset of the movements was calculated by a specific routine developed at MATLAB ${ }^{\circledR}$ and was recorded when the angular velocity was positive and the displacement exceeded one degree and remained constant ${ }^{8}$, whereas its termination was considered when the displacement returned to the mean values after the movements were terminated. The duration of both the muscular activity and the movement were calculated, and a ratio between them, or their duration ratios, were determined to allow for comparisons between groups and individuals performing the movements with different durations.

\section{Data analysis}

Descriptive statistics and tests for normality were calculated for all outcome variables, using the software SPSS 13.0 for Windows (SPSS Inc. ${ }^{\odot}$, Chicago, IL). According to the data distribution, Student $t$-tests or Mann-Whitney- $U$ tests were employed to investigate differences between the groups regarding their latencies, the duration ratio, and the amount of activation (\% of peak 
EMG values) of the extensors of the trunk and hip joints. Repeated measure ANOVAs were used to compare the latencies of each muscle within the groups with a significance level of $\alpha<0.05$.

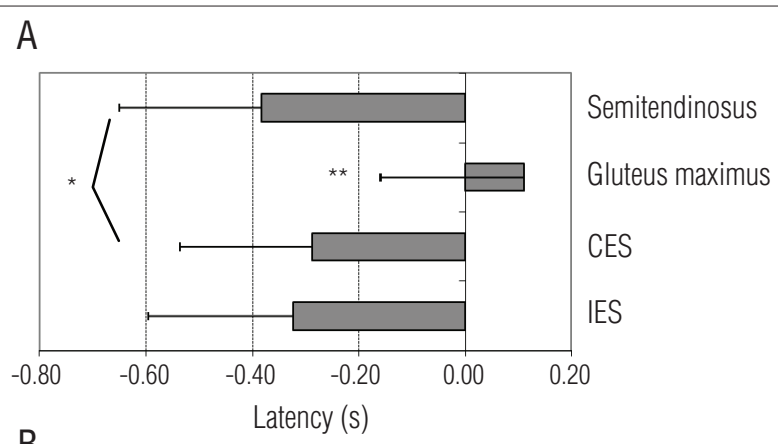

B

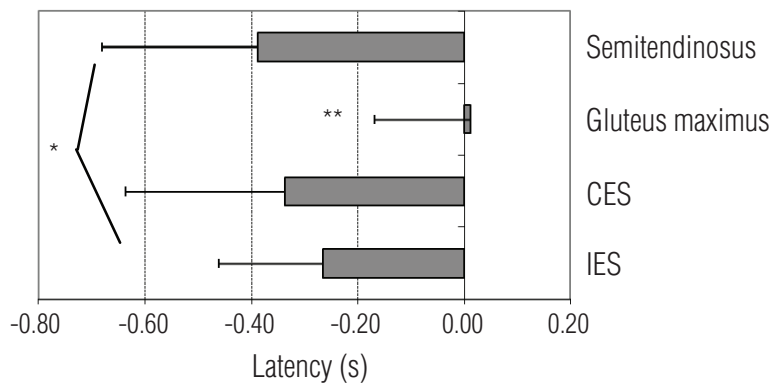

${ }^{*} \mathrm{p}<0.05 ;{ }^{* *} \mathrm{p}<0.01$; IES=Ipsilateral erector spinae; CES=Contralateral erector spinae

Figure 2. Muscular latencies of all investigated muscles for the asymptomatic $(A)$ and LBP $(B)$ individuals.

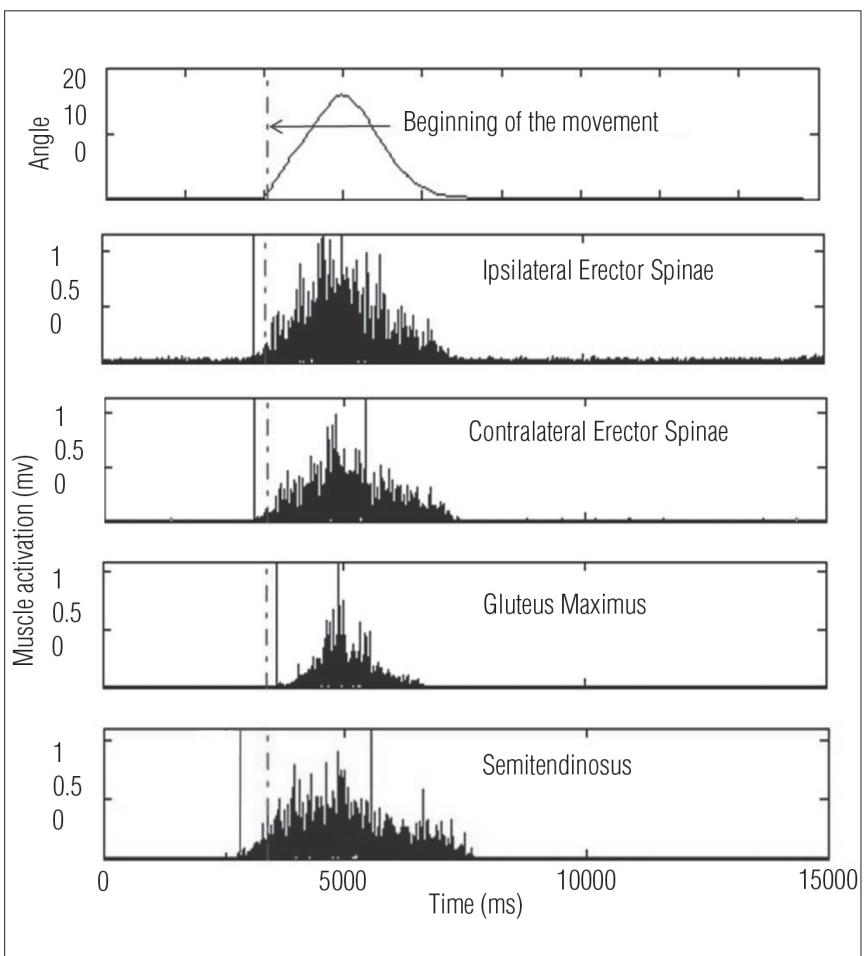

Figure 3. A typical activation pattern of an individual with LBP, determined by the onset of EMG activity. The dotted lines represent the beginning of the movement and the straight lines the beginning of the muscular activity.
Results $: \because$.

\section{Subject characteristics}

For the matching of the groups by their physical activity levels, three individuals of the asymptomatic group were excluded. Moreover, one individual from the LBP group complained of pain during the assessment, and was also excluded. Therefore, only 46 subjects participated in the study, with 27 asymptomatics and 19 with LBP (55.6\% women and $44.4 \%$ men). The asymptomatic group had a mean age of $24.85 \pm 3.60$ years, a body mass of $67.36 \pm 12.55 \mathrm{~kg}$, a height of $1.70 \pm 0.09 \mathrm{~m}$, and a body mass index (BMI) of $23.13 \pm 3.09 \mathrm{~kg} / \mathrm{m}^{2}$.

The LBP group had a mean age of $28.79 \pm 5.67$ years, body mass of $66.92 \pm 16.76 \mathrm{~kg}$, height of $1.68 \pm 0.09 \mathrm{~m}$ and BMI of $23.48 \pm 3.84 \mathrm{~kg} / \mathrm{m}^{2}$. These individuals had complaints of pain for periods ranging from one to 10 years ( $3.5 \pm 2.38$ years). Seven complained of pain in the direction of extension, three in the direction of flexion, seven in both directions, and two did not show any specific patterns. Clinically, these individuals had a score of 28.58 [19-38] on the Tampa Scale for Kinesiophobia; 4.74 [0-11] on the Rolland Morris questionnaire and 1.63 [0-3] on the qualitative pain scale, indicating that the individuals had low levels of kinesiophobia, functional limitations and pain.

\section{Outcome measures}

Figure 2 shows the muscular latencies of all investigated muscles for the asymptomatic (2a) and LBP (2b) individuals. For the asymptomatic group, the muscular activation patterns were initiated by the semitendinosus, followed by the ipsilateral erector spinae, contralateral erector spinae and finished by the gluteus maximus. The ANOVAs demonstrated significant differences in the latencies for the semitendinosus in relation to the contralateral erector spinae $(F=13.91 ; p=0.001)$ and gluteus maximus $(F=56.34 ; p<0.001)$, indicating that the semitendinosus was the first muscle to be activated. Significant differences were also observed for the gluteus maximus latencies in relation to the other muscles ( $F>41.78$; $p<0.001)$, demonstrating that the gluteus maximus was the last muscle to be activated (Figure 2A).

For the LBP group, the activation sequences were also initiated with the semitendinosus, followed by the contralateral erector spinae, ipsilateral erector spinae and gluteus maximus (Figure 3). As shown in Figure 2B, similar to the asymptomatic group, significant delays were also observed for the onset times of the gluteus maximus in comparison to the other muscles $(F>23.64 ; p<0.001)$. The ANOVAs also revealed significant differences in latencies for the semitendinosus in relation to the ipsilateral erector spinae $(F=7.49 ; p=0.014)$ and gluteus maximus muscles $(F=36.70 ; p<0.001)$. 
As is shown in Table 1, no significant differences were found between the groups regarding the variables related to the latencies $(0.28<z / t<1.37 ; 0.18<p<0.78)$, amount of activation $(0.14<z / t<1.14 ; 0.26<p<0.89)$, and duration of activation $(0.02<z / t<1.63 ; 0.10<p<0.98)$ for all investigated muscles. In addition, no interaction effects were found between genders nor physical activity levels for any investigated variables for both groups $(0.03<F<1.14 ; 0.28<p<0.87)$.

\section{Discussion $\because \because$.}

Evaluations of the active prone hip extension have been extensively carried out, based upon the existence of consistent activation patterns of the trunk and hip extensor muscles. The ideal pattern was believed to be characterized by the initial activation of the gluteus maximus, followed by the hamstring and erector spinae muscles ${ }^{1,2}$. In the present study, however, this pattern was not observed in either of the evaluated groups. Actually, the most consistent findings were the delayed activation of the gluteus maximus in relation to the other muscles. Furthermore, comparisons between the asymptomatic and LBP individuals did not reveal significant differences for any of the investigated EMG parameters.
For both groups, an activation sequence was observed, which was initiated by the semitendinosus, followed by the erector spinae muscles (ipsilateral and then contralateral for the asymptomatic; contralateral and then ipsilateral for the LBP) and finally by the gluteus maximus. Previous studies which evaluated asymptomatic individuals also reported initial activation of the hamstrings ${ }^{7,8}$, although only Sakamoto et al. ${ }^{8}$ found significant differences in the latency of these muscles in relation to the other hip and trunk extensor muscles. On the other hand, Vogt and Banzer ${ }^{9}$ observed different activation sequences, initiated by the ipsilateral erector spinae, followed by the contralateral erector spinae, hamstrings and gluteus maximus muscles.

Although previous studies showed some differences regarding the order of activation of the hamstrings and the erector spinae muscles, there was a consensus that the gluteus maximus was the last muscle to be activated ${ }^{6-9}$, suggesting that this delay appears to be a normal finding. One theoretical hypothesis, based upon anatomical and biomechanical knowledge, is that these delays could lead to movement impairments, favoring the occurrence of pelvic anteversion and excessive lumbar extension, generating excessive stresses in the spine $e^{1,2,4}$. Furthermore, decreases in the gluteus maximus activation could compromize the

Table 1. Descriptive statistics, critical value, and $p$ values of the investigated EMG parameters for the asymptomatic (A) and LBP groups.

\begin{tabular}{|c|c|c|c|c|c|c|}
\hline Variable & Muscle & Group & Median & Confidence Interval & Critical Value & $p$ \\
\hline \multirow[t]{8}{*}{ Latency (s) } & \multirow[t]{2}{*}{ IES } & A & -0.26 & {$[-0.45 ;-0.21]$} & \multirow[t]{2}{*}{$z=-0.42$} & \multirow[t]{2}{*}{0.68} \\
\hline & & LBP & -0.22 & {$[-0.32 ;-0.15]$} & & \\
\hline & \multirow[t]{2}{*}{ CES } & A & -0.27 & {$[-0.41 ;-0.21]$} & \multirow[t]{2}{*}{$z=-0.28$} & \multirow[t]{2}{*}{0.78} \\
\hline & & LBP & -0.23 & {$[-0.48 ;-0.16]$} & & \\
\hline & \multirow[t]{2}{*}{ Gluteus } & A & 0.11 & {$[0.02 ; 0.25]$} & \multirow[t]{2}{*}{$t=1.37$} & \multirow[t]{2}{*}{0.18} \\
\hline & & LBP & -0.004 & {$[-0.06 ; 0.10]$} & & \\
\hline & \multirow[t]{2}{*}{ Semit } & A & -0.34 & {$[-0.50 ;-0.26]$} & \multirow[t]{2}{*}{$z=-0.29$} & \multirow{2}{*}{0.77} \\
\hline & & LBP & -0.30 & {$[-0.49 ;-0.22]$} & & \\
\hline \multirow[t]{4}{*}{ Amount of activation (\%) } & \multirow[t]{2}{*}{ IES } & A & 11.48 & {$[10.49 ; 12.65]$} & \multirow[t]{2}{*}{$t=-0.14$} & \multirow[t]{2}{*}{0.89} \\
\hline & & LBP & 11.99 & {$[10.47 ; 13.75]$} & & \\
\hline & \multirow[t]{2}{*}{ CES } & A & 11.36 & {$[10.30 ; 12.53]$} & \multirow[t]{2}{*}{$t=-0.28$} & \multirow[t]{2}{*}{0.78} \\
\hline & & LBP & 12.39 & {$[10.63 ; 13.14]$} & & \\
\hline \multirow{12}{*}{$\begin{array}{l}\text { Duration of activation } \\
\text { (ratio: duration of activation/ } \\
\text { movement duration) }\end{array}$} & \multirow[t]{2}{*}{ Gluteus } & A & 8.02 & {$[7.22 ; 8.77]$} & \multirow[t]{2}{*}{$\mathrm{t}=-0.72$} & \multirow[t]{2}{*}{0.48} \\
\hline & & LBP & 9.35 & [7.92; 10.43] & & \\
\hline & \multirow[t]{2}{*}{ Semit } & A & 10.58 & [9.88; 12.15] & \multirow[t]{2}{*}{$t=-1.14$} & \multirow[t]{2}{*}{0.26} \\
\hline & & LBP & 11.99 & {$[11.03 ; 14.31]$} & & \\
\hline & \multirow[t]{2}{*}{ IES } & A & 1.37 & {$[1.34 ; 1.57]$} & \multirow[t]{2}{*}{$z=-1.63$} & \multirow[t]{2}{*}{0.10} \\
\hline & & LBP & 1.28 & {$[1.17 ; 1.33]$} & & \\
\hline & \multirow[t]{2}{*}{ CES } & A & 1.42 & {$[1.36 ; 1.55]$} & \multirow[t]{2}{*}{$z=-0.57$} & \multirow[t]{2}{*}{0.57} \\
\hline & & LBP & 1.41 & {$[1.25 ; 1.46]$} & & \\
\hline & Gluteus & A & 1.04 & {$[0.99 ; 1.16]$} & $t=-1.68$ & 0.10 \\
\hline & & LBP & 1.26 & {$[1.14 ; 1.33]$} & & \\
\hline & Semit & A & 1.44 & {$[1.39 ; 1.59]$} & $z=-0.02$ & 0.98 \\
\hline & & LBP & 1.46 & {$[1.37 ; 1.56]$} & & \\
\hline
\end{tabular}


stability of the sacroiliac joint during functional activities and predispose it to pain ${ }^{15,16}$.

Considering this hypothesis, it could be expected that individuals with mechanical LBP would show increased delays and decreased durations and amounts of activation of the gluteus maximus, compared to the asymptomatic individuals, who were not observed in the present study. These findings, however, deserve some considerations.

Health conditions such as LBP are considered multifactorial, which means that several factors may exist, which are both mechanical and non-mechanical associated with the onset, recurrence, or exacerbation of pain ${ }^{17}$. The mechanical factors may include muscular weaknesses and shortening, changes in movement and activation patterns, incorrect postural habits, repetitive movements employed in work or sport activities, ergonomic and environmental factors. All of these represent intrinsic and extrinsic risk factors which may help the understanding of the causes of specific dysfunctions ${ }^{17,18}$. Changes in activation patterns represent only one of several risk factors for lumbar spine dysfunctions. Thus, it is possible that changes in the activation patterns could be observed in individuals without pain, making it difficult to find differences between groups.

Another consideration refers to the characteristics of the LBP participants: They had low levels of kinesiofobia and pain and did not have disabilities. It is possible that individuals with greater functional limitations would show changes in muscular activation parameters which would agree with the reports of previous studies ${ }^{19-22}$. However, the selection of participants with these characteristics was a deliberate decision, since the aim of the present study was to understand the relationships between changes in the activation patterns and mechanical LBP, and not the effects of high levels of pain and disabilities of muscular activity.

In any case, the fact that significant differences were not found, suggests that the evaluation of electromyographic activity during active prone hip extension was not capable of discriminating between individuals with and without LBP, as suggested by Lehman ${ }^{23}$. This ability would be even more difficult in clinical environments, where the evaluation is performed in a subjective way through muscular palpation.

Some methodological considerations need to be discussed. In the present study, the onset of electromyographic activity was considered to occur when the values exceeded two standard deviations from the mean values observed at baseline for a $50 \mathrm{~ms}$ period ${ }^{8}$. This method has been demonstrated to be reliable, when compared to others, and helps the avoidance of type I (when using one standard deviation) and type II (using three standard deviations) methodological errors, as reported by Hodges and Bui ${ }^{14}$.

The EMG data obtained during the performance of prone hip extension was normalized by the peak values obtained during the complete movement. These procedures allowed comparisons between different individuals and studies and reduced the inter-subject coefficients of variation ${ }^{24}$. Normalization by the maximum voluntary contractions was not chosen, as previously employed ${ }^{25}$, because this procedure could not have been trustworthy for individuals with LBP, as they would not be able to perform maximum contractions due to the pain ${ }^{26-29}$.

\section{Clinical considerations}

Considering the high variability observed in the electromyographic activation parameters during prone hip extension, two factors should be discussed. The first one refers to the difficulty in defining an ideal activation pattern, which could be used as a reference point for comparisons. This pattern is probably different for each individual, according to their own characteristics.

The second factor is that, in the evaluation of active prone hip extension, the movement patterns rather than the activation parameters, should be evaluated to identify changes such as pelvic anteversion or rotation which could generate excessive stress and pain in the spine ${ }^{30}$.

\section{Conclusions $: \because$.}

Comparisons between asymptomatic and LBP individuals did not reveal significant differences, regarding the latencies, durations and amount of EMG activation of the trunk and hip extensor muscles during active prone hip extension movements. Therefore, the evaluation of the electromyographic activity was not capable of discriminating between the individuals with and without LBP, suggesting interactions between the studied populations.

\section{Acknowledgments $: \therefore$.}

Brazilian GovernmentFunding Agencies (Conselho Nacional de Desenvolvimento Científico e Tecnológico/Fundação de Amparo à Pesquisa do Estado de Minas Gerais - CNPq/ FAPEMIG). 


\section{References $: \because$.}

1. Comerford MJ, Mottram SL. Movement and stability dysfunction: Contemporary developments. Man Ther. 2001;6(1):15-26.

2. Sahrmann SA. Diagnosis and treatment of movement impairment syndromes. $1^{\text {a }}$ ed. St Louis: Mosby; 2002.

3. Mueller MJ, Maluf KS. Tissue adaptation to physical stress: A proposed "physical stress theory" to guide physical therapist practice, education, and research. Phys Ther. 2002;82(4):383-403.

4. Bullock-Saxton J, Murphy D, Norris C, Richardson C, Tunnell P. The muscle designation debate: The experts respond. J Bodywork Mov Ther. 2000;4:225-41.

5. McGill SM, Grenier S, Kavcic N, Cholewicki J. Coordination of muscle activity to assure stability of the lumbar spine. J Electromyogr Kinesiol. 2003;13(4):353-9.

6. Lehman GJ, Lennon D, Tresidder B, Rayfield B, Poschar M. Muscle recruitment patterns during the prone leg extension. BMC Musculoskelet Disord. 2004;5:3.

7. Nygren Pierce M, Lee WA. Muscle firing order during active prone hip extension. J Orthop Sports Phys Ther. 1990;12(1):2-9.

8. Sakamoto AC, Teixeira-Salmela LF, de Paula-GoulartFR, de Morais Faria CD, Guimarães CQ. Muscular activation patterns during active prone hip extension exercises. J Electromyogr Kinesiol. 2009;19(1):105-12.

9. Vogt L, Banzer W. Dynamic testing of the motor stereotype in prone hip extension from neutral position. Clin Biomech. 1997;12(2):122-7.

10. Matsudo S, Araújo T, Marsudo V, Andrade D, Andrade E, Oliveira LC, et al. Questionário internacional de atividade física (IPAQ): Estudo de validade e reprodutibilidade no Brasil. Rev Bras Ativ Fís Saúde. 2001;6(2):5-18

11. Siqueira FB, Teixeira-Salmela LF, Magalhães LC. Análise das propriedades psicométricas da versão brasileira da Escala Tampa de cinesiofobia. Acta Ortop Bras. 2007;15(1):19-24.

12. Nusbaum L, Natour J, Ferraz MB, Goldenberg J. Translation, adaptation and validation of the Roland-Morris questionnaire - Brazil Roland-Morris. Braz J Med Biol Res. 2001;34(2):203-10.

13. Cram CL, Kasman GS, HoltzJ. Introduction to surface electromyography. $1^{\text {a }}$ ed. Maryland: Aspen; 1998.

14. Hodges PW, Bui BH. A comparison of computer-based methods for the determination of onset of muscle contraction using electromyography. Electroencephalogr Clin Neurophysiol. 1996;101(6):511-9.

15. Hossain M, Nokes LD. A model of dynamic sacro-iliac joint instability from malrecruitment of gluteus maximus and biceps femoris muscles resulting in low back pain. Med Hypotheses. 2005;65(2):278-81.

16. Vleeming A, Mooney V, Dorman T, Snijders C, Stoeckart R. Movement, stability and low back pain: The essencial role of the pelvis. $2^{a}$ ed. London: Harcourt; 1999.
17. O'Sullivan P. Diagnosis and classification of chronic low back pain disorders: maladaptive movement and motor control impairments as underlying mechanism. Man Ther. 2005;10(4):242-55.

18. Bahr R, Krosshaug T. Understanding injury mechanisms: A key component of preventing injuries in sport. British J Sports Med. 2005;39(6):324-9.

19. Kankaanpaa M, Taimela S, Laaksonen D, Hanninen O, Airaksinen O. Back and hip extensor fatigability in chronic low back pain patients and controls. Arch Phys Med Rehabil. 1998;79(4):412-7.

20. Leinonen V, Kankaanpaa M, Airaksinen 0, Hanninen 0. Back and hip extensor activities during trunk flexion/extension: effects of low back pain and rehabilitation. Arch Phys Med Rehabil. 2000;81(1):32-7.

21. Radebold A, Cholewicki J, Panjabi MM, Patel TC. Muscle response pattern to sudden trunk loading in healthy individuals and in patients with chronic low back pain. Spine (Phila Pa 1976). 2000;25(8):947-54.

22. Dankaerts W, O'Sullivan $P$, Burnett $A$, Straker $L$. Altered patterns of superficial trunk muscle activation during sitting in nonspecific chronic low back pain patients: importance of subclassification. Spine (Phila Pa 1976). 2006;31(17):2017-23.

23. Lehman GJ. Trunk and hip muscle recruitment patterns during the prone leg extension following a lateral ankle sprain: A prospective case study pre and post injury. Chiropractic Osteopathy. 2006;14(4):1-4.

24. Soderberg GL, Knutson LM. A guide for use and interpretation of kinesiologic electromyographic data. Phys Ther. 2000;80(5):485-98.

25. Sakamoto ACL, Teixeira-Salmela LF, Rodrigues de Paula F, Guimarães CQ, Faria CDCM Gluteus maximus and semitendinosus activation during active prone hip extension exercises. Rev Bras Fisioter. 2009;13(4):335-42.

26. van Dieen JH, Selen LP, Cholewicki J. Trunk muscle activation in low-back pain patients: An analysis of the literature. J Electromyogr Kinesiol. 2003;13(4):333-51.

27. Vogt L, Pfeifer K, Banzer W. Neuromuscular control of walking with chronic low-back pain Man Ther. 2003;8(1):21-8.

28. van Dieen JH, Cholewicki J, Radebold A. Trunk muscle recruitment patterns in patients with low back pain enhance the stability of the lumbar spine. Spine (Phila Pa 1976). 2003;28(8):834-41.

29. Hungerford B, Gilleard W, Hodges P. Evidence of altered lumbopelvic muscle recruitment in the presence of sacroiliac joint pain. Spine (Phila Pa 1976). 2003;28:1593-600.

30. Ferguson SA, Marras WS, Burr DL, Davis KG, Gupta P. Differences in motor recruitment and resulting kinematics between low back pain patients and asymptomatic participants during lifting exertions. Clin Biomech. 2004;19(10):992-9. 